\title{
THERMAL PERFORMANCE OF A PROTOTYPE QUONSET-SHAPED SOLAR COOKER
}

\author{
M. A. Tawfik*
}

\section{ABSTRACT}

The aim of this work is studied the thermal performance of a local made prototype Quonset-shaped solar cooker provided with an transparent fiberglass sheets under the local climatic conditions of Zagazig city, Egypt (Lat. $30^{\circ} 35^{\backslash} \mathrm{N}$; Lon. $31^{\circ} 31^{\backslash}$ E). The Quonset geometric shape of the cooker cover was chosen to obtain a large enclosure volume to increase the accumulated solar heat inside the cooking compartment. The cooker was divided into two equal compartments with aperture area 0.12 $\mathrm{m}^{2}$ and provided with internal solar reflective films. The Thermal performance of cooker was evaluated using the conventional absorber plate (CAP) and black stones pebbles bed (BSB) with different water loads and under the passive and active (the integration of the cooker with a solar flat-plate collector and PV system) modes with taking into consideration the first figure of merit, utilizable efficiency, specific and characteristic boiling times. The results revealed that, the solar cooker with CAP achieved stagnation temperature of about $10 \%$ more than the $B S B$ cooker with delay 40 min and first figure of merit of $0.12{ }^{\circ} \mathrm{C} . \mathrm{m}^{2} / \mathrm{W}$, whereas the CAP was $0.11^{\circ} \mathrm{C} . \mathrm{m}^{2} / \mathrm{W}$. The active solar cooker with $C A P$ achieved the highest utilizable efficiency of $36.6 \%$ with an increment by about $26.5 \%$ than the passive one at the maximum water load of $1.50 \mathrm{~kg}$, while the utilizable efficiency of the solar cooker with BSB was 22.52 and $26.9 \%$ for the passive and active modes, respectively. Hence, It is recommended to use the active solar cooker with CAP to achieve a good thermal performance because this cooker with aperture area of $1 \mathrm{~m}^{2}$ can boil $1 \mathrm{~kg}$ of water in about $18 \mathrm{~min}$ at utilizable efficiency of $25 \%$ which reduced the boiling time by about $21.74 \%$, whereas the passive cooker with BSB is useful when the evening cooking is concerned and it is not recommended to use this cooker in active mode

Keywords: Quonset-shaped solar cooker, transparence fiberglass, black stones, flat-plate collector, PV system, thermal performance

"Ass. Professor, Agric. Eng. Dept., Fac. of Agric., Zagazig Univ., Egypt 


\section{INTRODUCTION}

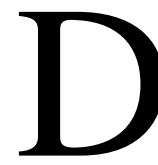

espite the fossil fuels such as; coal, petroleum, LPG and natural gas have harmful effect on environment and may be depleted in the nearby future, most of the energy demands are met by these fuels. Thus, the concept of utilizing the renewable energy and decreasing of the dependence on fossil fuels for producing heat and electricity was raised in the few last decades and till now. One of the most potential renewable energy is the solar energy as an abundant, green and sustainable source. Egypt is endowed with high daily solar radiation intensity ranging between $5.5-7 \mathrm{kWh} / \mathrm{m}^{2}$ from north to south and more than 270 of sunny days every year due to its unique location in the world Sunbelt which makes the country very potential to exploit the solar energy in several applications within the farm. So, this can give perspective of the necessity to collect and trap the solar energy in economical and effective way. Among the various applications, solar cooking is considered very promising methods for exploiting the high intensity of solar radiation especially in the case of absence of the conventional energy resources, particularly in rural, remote and isolated areas and consequently, there is no need to transport the fossil fuels such as the LPG cylinders from urban areas. In the mentioned areas, the energy required for cooking is almost fulfilled by noncommercial fuels sources such as; firewood, agricultural residues, and animal dung and kerosene (Wentzel and Pouris, 2007). The importance of the solar cooker is intruding as a sustainable method for cooking in addition to reduce the recurring cost, efforts and preserve the nutritional value of food with high durability in structure (Muthusivagami et al., 2010). In recent years, there are many attempts by researchers over the globe to improve the thermal performance of the solar cooker via novel styles and techniques not for cooking food only but for other significant processes like pasteurization or sterilization, however the solar cookers can be classified into three main types called the box, panel and parabolic cookers (Cuce and Cuce, 2015). Numerous external and internal modifications were performed to develop the thermal performance to make the conventional solar cooker (particularly the box type) more effective such as; double exposure cooker design (Harmim et al., 2008a), external and internal 
reflectors (Mirdha and Dhariwal, 2008; Terres et al., 2014), tilted (Harmim et al.,2010) and finned absorber plate (Cuce and Cuce, 2013), modified pot (Narasimha and Subramanyam, 2005; Harmim, et al., 2008b), PCM thermal storage (Hussein et al., 2008), latent heat storage (Nahar, 2003; Budhi et al., 2003), transparent insulation (Nahar, 2001; Kalogirou, 2004) cover, in addition to other countless modifications. Additionally, the uncommon solar cooker styles were contributed in increasing the incident solar radiation through different geometric shapes like the cylindrical absorber in the car-tire solar cooker augmented with mirror (Hanan, 2016), conical solar cooker (Kerdchang and Puangsombut, 2008) and Fresnel lens (Valmiki et al., 2011). The impacts of these modifications are effective in case of small volume of the cooking insulated compartment. It is known that, the large enclosure volume within the cooker means increasing the incident solar radiation on the pot and the absorber plate which may accumulate the heat. In the same time, this can encourage the convection heat transfer and increase heat loss through the glass glazing to ambient (Akhtar and Mullick, 1999) due to the emission of long waves rays from the absorber towards the glazing cover and then the thermal performance of cooker will be retarded. Since the incident area of solar radiation, overall coefficient of heat loss, and thermal conductivity of the absorber determine the cooking performane (Funk and Larson, 1998), thus there is an urgent need to investigate the possibility of enhancement the thermal performance of the solar cooker with a large cooking compartment and intercept area and using effective modifications, practically this implies more pot's loads and fast cooking process. Due to the curved shape covers allow to enter as much solar radiation as possible to the cooking compartment and consequently enlarging the solar radiation intercept area, so the present work is focused on using a prototype of Quonset-shaped solar cooker to expose the pot and large area of the absorber plate to maximum radiation for securing an increment in the trapped heat in the cooking compartment. Simultaneously, to avoid the heat losses to surrounding due to the increase of cooker cover surface area, the transparent insulating (TI) cover is recommended in order to enhance the cooker thermal efficiency(Kalogirou, 2003). IT materials are ordinarily featured by low 
thermal conductivity, high solar radiation transmittance and low emissivity (Dudko, 2004). Accordingly, IT material helps to accumulate heat on the absorber plate surface (Lewandowski and LewandowskaIwaniak, 2014), this means additional gains of solar heat (Kisilewicz, 2007) and accordingly enhances the capability to store the thermal energy (Kaushika and Sumathy, 2003).Among various IT materials, the transparent Fiberglass one of the most effective insulating material due to its lightweight, durability, formability, low thermal conductivity. Regarding the solar radiation transmittance, it performs like the conventional glass but with slightly less transmittable of $80 \%$ versus $87 \%$ for glass (Zulovich, 1993).Furthermore, the addition of heat storage materials such as; water, rocks, pebbles, PCMs, and etc. can be useful for evening cooking (Cuce and Cuce, 2013). Hence, this paper aims to investigate the thermal performance of the integrated prototype Quonsetshaped solar cooker with a flat-plate collector and photovoltaic (PV) system using the conventional absorber plate and black stones bed under the passive and active modes.

\section{MATERIALS AND METHODS}

The experiments of this study were carried to investigate the thermal performance of a solar cooking system under the climatic condition of Zagazig City, northern east Delta, Egypt (Lat. $30^{\circ} 35 \%$, Long. $31^{\circ} 31$ \% $E$ ) during August 2017. This system includes a prototype Quonset-shaped solar cooker provided with fiberglass cover and internal reflectors integrated with flat-plate solar collector and photovoltaic system.

\section{The experimental setup}

1.1. The cooking pots: Two similar ordinary central annular cavity cooking pots were used during the experimental days. The diameters of each pot were $245 \mathrm{~mm}$ at top $150 \mathrm{~mm}$ at bottom and $100 \mathrm{~mm}$ in depth. The pot and the concave lid were painted with synthetic black matt paint from outside to increase its solar heat absorbance. The pot's lid has a sealed hole with $1 \mathrm{~mm}$ in diameter to pass the thermocouple sensor into the pot's depth for measuring the water temperature. 
1.2. The solar cooking system: The solar cooking system mainly consists of the prototype Quonset solar cooker, solar flat-plate collector, connection pipes, pump and PV system, as illustrated in Fig.(1).

\subsubsection{The prototype Quonset solar cooker}

1.2.1.1 The absorber plate and the black stones: The prototype of the Quonset solar cooker was constructed in local workshop at Zagazig city, Egypt. The solar cooker has rectangular absorber plate that made of galvanized iron sheet with $0.12 \mathrm{~cm}$ in thickness and $10 \mathrm{~cm}$ in depth. The absorber was fabricated with inner net area of $0.27 \mathrm{~m}^{2}$ (90 Length $\times 30$ Width in $\mathrm{cm}$ ). The surfaces of bottom and the inside-walls were painted with black matt paint. Black stones pebbles with $30-40 \mathrm{~mm}$ in size were used over the conventional absorber plate.

1.2.1.2. The wooden container: The absorber was placed in rectangular wooden container made of counter wood with $2 \mathrm{~cm}$ in thickness, $25 \mathrm{~cm}$ in inner depth and overall outer dimensions of 104Length $\times 44$ width $\mathrm{cm}$. The wooden container was placed on four poles at height of $60 \mathrm{~cm}$ above the ground.

1.2.1.3. The Quonset cover:A Quonset-shaped glazing cover ( as depicted in Fig. 1-a) was made of plain transparent fiberglass sheets (made in China) with thermal conductivity coefficient of $0.033 \mathrm{~W} / \mathrm{m} .{ }^{\circ} \mathrm{C}$, density $1.5 \mathrm{~g} / \mathrm{cm}^{3}$, transmissivity $85 \%$ and operating range $-60-150^{\circ} \mathrm{C}$. The cover was formed with overall dimensions of $40 \times 100 \mathrm{Lcm}$ A thermal gasket was placed between the cover and the wooden container to prevent the heat loss to atmosphere.

1.2.1.4 The internal reflectors: The solar cooker was divided into two equal compartments with aperture area $(40 \mathrm{~cm}$ in length and $30 \mathrm{~cm}$ for the surface area $\left(0.12 \mathrm{~m}^{2}\right)$ for each by using polystyrene panel with $10 \mathrm{~cm}$ in thickness, as shown in Fig.(2). The double faces of the panel were coated by two special solar reflective films with $0.010 \mathrm{~cm}$ in thickness. It is a back glue films with reflective rate $97 \%$ (According the manufacturermade in China). Furthermore, the both sides and the back surface were coated with the same paper to increase the trapped solar radiation inside the cooking compartment. As general, the solar cooker was faced south to be subjected to the solar radiation as long as possible throughout daylight. 
1.2.1.5. The internal heat exchanger (IHE): An IHE was welded on the outside surface of the absorber plate bottom. For active mode, The IHE was made from copper tubes with an internal diameter of $0.781 \mathrm{~cm}$, external diameter of $0.953 \mathrm{~cm}$ and separated by $10 \mathrm{~cm}$ interval distances. The absorber plate with the IHE were coated from outside with $5 \mathrm{~cm}$ of compact ceramic insulator to prevent the heat loss to the ambient air.

\subsubsection{The solar flat-plate collector}

Concerning the active mode of cooking system as depicted in Fig. (1-b), the solar flat-plate collector was fabricated with rectangular shape with overall area of $2 \mathrm{~m}^{2}(200 \times 100 \mathrm{~cm})$. The absorber plate was made of the galvanized iron sheet with $0.20 \mathrm{~cm}$ in thickness and side wall depth of $4 \mathrm{~cm} .18$ of copper pipes with outer and inner pipes diameters equal to 1.5 and $0.79 \mathrm{~cm}$, respectively were fixed on the absorber horizontally. The surface of absorber and copper pipes were painted with black matt paint. The absorber and its pipes were covered by glass panel with $0.30 \mathrm{~cm}$ and placed in wooden container with $2 \mathrm{~cm}$ thickness. The glass wool was packed with $7 \mathrm{~cm}$ in thickness between the absorber and the container. The flat-plate solar collector was faced to south and inclined with $30^{\circ}$ (equal to Zagazig city latitude) on horizontal.

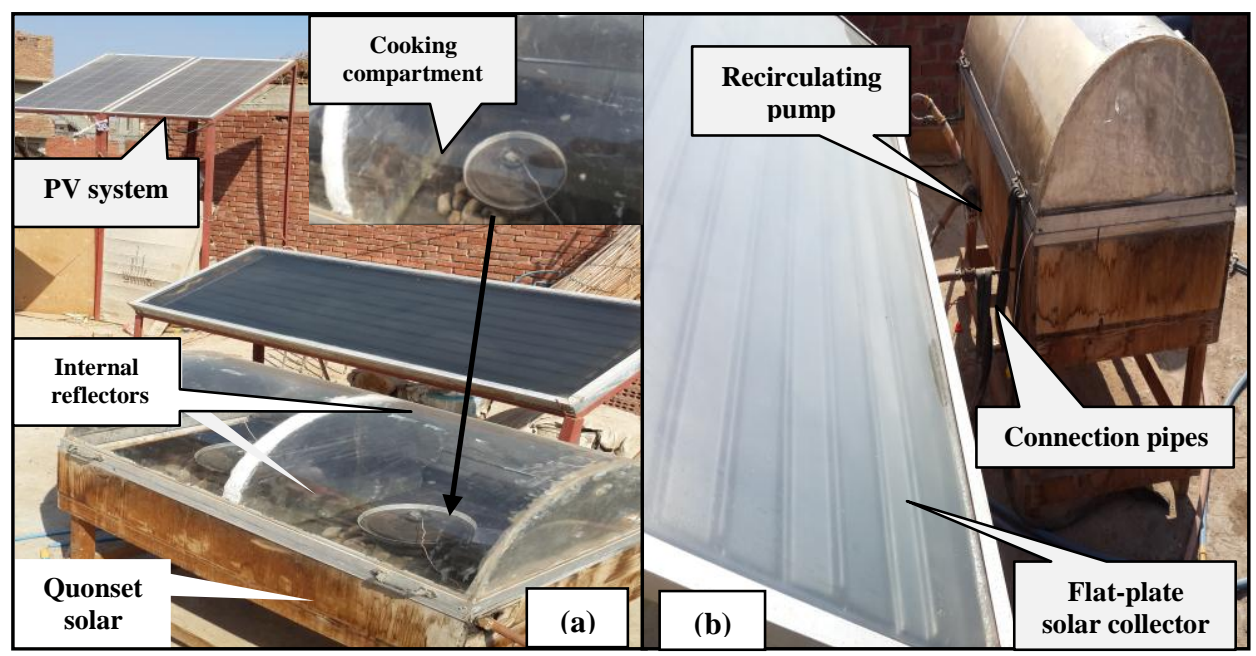

Fig.(1): The solar cooking system a) the integrated Quonset solar cooker with flat-plate collector and PV system ;b) pump and connection pipes. 


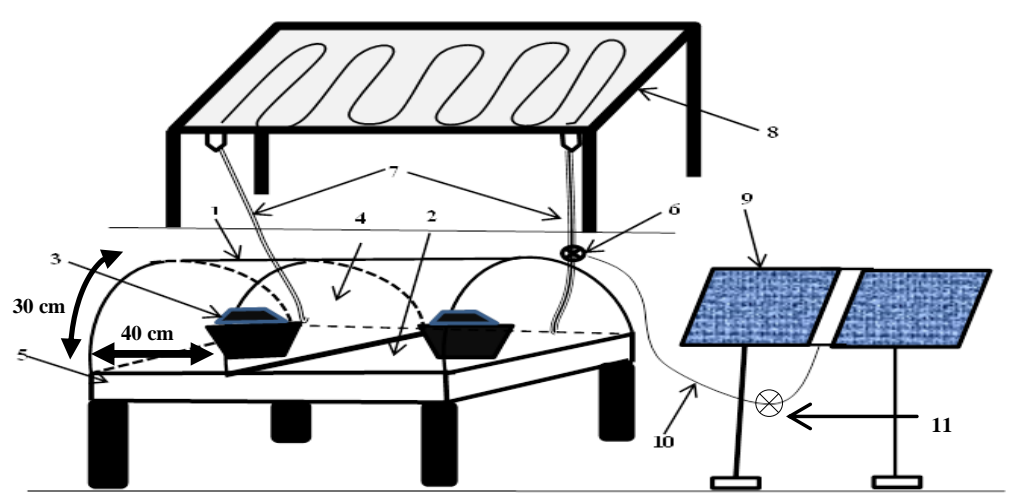

Fig.(2):Schematic diagram of the solar cooking system in active mode 1- Fiberglass cover, 2- Absorber plate, 3-Pot, 4- Solar reflective paper, 5-Wooden container, 6- recirculating pump, 7-Connection pipes, 8- Flat-plate collector,9- PV module, 10-Electric wire, 11-current converter

\subsubsection{The connecting pipes and pump}

(All the connection pipes were made of isolated rubber to join the solar flat-plate collector and the prototype Quonset solar cooker during the active mode ,s shown in Fig.(2). In this mode, the solar flat-plate collector would provide the cooking system with the hot water by using recirculating pump with flow rate of $0.41 \mathrm{~L} / \mathrm{s}$ through the connection pipes . This pump is AC centrifugal pump with power of $40 \mathrm{~W}$.

\subsubsection{Photovoltaic (PV) system}

The PV system was integrated with the solar cooker to be sustainable system in the areas without conventional electricity, as illustrated in Fig.(2).A polycrystalline PV module was used that can generate 0.350 $\mathrm{kWh} /$ day of electrical energy which is adequate for operating the recirculating pump throughout the day. The generated DC by the PV module was converted to AC using current convertor (600 W).

\section{2- Methods}

\subsection{The experimental procedures}

All practical experiments were performed to evaluate the thermal performance of the prototype Quonset solar cooking system under the passive and active mode. In the passive mode tests, the solar cooker received the heat from the solar radiation only. In active mode, the cooker received hot water by the integration with the flat-plate solar collector. 
Generally, the solar cooking system was investigated under the followings:

1- Three water loads of $0.5,1$ and $1.50 \mathrm{~kg}$

2- Using the black stones bed (BSB) as absorbed material comparing with the conventional absorber plate (CAP).

3- The passive and active modes.

\subsection{Measuring and Determinations}

\subsubsection{Temperature and solar radiation intensity}

For each compartment, the temperatures of the ambient $\left(\boldsymbol{T}_{a m}\right)$, absorber plate $\left(\boldsymbol{T}_{p}\right)$, enclosure air $\left(\boldsymbol{T}_{e}\right)$, water inside the pot $\left(\boldsymbol{T}_{w}\right)$, inner $\left(\boldsymbol{T}_{c i}\right)$ and outer $\left(\boldsymbol{T}_{c o}\right)$ surface of cover were measured using K-type thermocouple sensors were plugged to the multi-channels digital data logging thermometer (Model: TM747 DU 4-Channel, Taiwan) with resolution of $0.1^{\circ} \mathrm{C}$. Moreover, the outputted hot water from the solar flat-plate collectors was measured. The solar radiation intensity was measured using solarimeter (TES-132,TENMARS, Taiwan), with measuring range of $0-2000 \mathrm{~W} / \mathrm{m}^{2}$, resolution $0.1 \mathrm{~W} / \mathrm{m}^{2}$ and accuracy $\pm 10 \mathrm{~W} / \mathrm{m}^{2}$. The whole experiments of this work were carried out when the wind velocity below $2.50 \mathrm{~m} / \mathrm{s}(9 \mathrm{~km} / \mathrm{h})$ (Funk, 2000).

\subsubsection{The first figure of merit $\left(F_{1}\right)$ :}

It is the ratio between the optical efficiency $\left(\eta_{o}\right)$ and the factor of total heat losses $\left(U_{L}\right)$.Where the increase of the optical efficiency on the account of total heat losses factor means better performance. This figure of merit can be determined by performing a test called the stagnation temperature. In this test the solar cooker is subjected to sunny and clear sky day without load (no pot) during period from 10:00 am to 14:00 pm. Once the absorber plate temperature in the solar cooker to be constant, this figure can be determined using the equation given by (Mullick, et al.1987):

$$
F_{1}=\frac{\eta_{o}}{U_{L}}=\frac{T_{P s}-T_{a s}}{H s}
$$

Where $F_{1}$ is the first figure of merit $\left({ }^{\circ} \mathrm{C} \cdot \mathrm{m}^{2} / \mathrm{W}\right)$, $\eta o$ is the optical efficiency (\%), $U_{L}$ is the overall heat loss factor $\left(\mathrm{W} /{ }^{\circ} \mathrm{C} \cdot \mathrm{m}^{2}\right), T_{p s}$ is the 
absorber plate temperature ( $\left.{ }^{\circ} \mathrm{C}\right), T_{a s}$ is the ambient temperature $\left({ }^{\circ} \mathrm{C}\right)$, and $H s$ is the solar radiation intensity on a horizontal surface $\left(\mathrm{W} / \mathrm{m}^{2}\right)$ at the absorber temperature stagnation time.

2.2.3 The utilizable efficiency of solar cooker $\left(\eta_{u}\right)$ :

The utilizable efficiency, $\eta_{u}(\%)$ is an important indicator to the amount of the exploited solar heat by the cooker (Mullick, et al.1996):

Where:

$$
\eta_{u}=\frac{(M C)_{w}\left(T_{w}-T_{a}\right)}{\bar{I}_{s} \cdot A_{p} \cdot \Delta t}
$$

$M$ mass of water, $\mathrm{kg} ; C$ specific heat of water $\left(4186 \mathrm{~J} / \mathrm{kg} .{ }^{\circ} \mathrm{C}\right) ; T_{w}$ maximum temperature of the load (water), ${ }^{\circ} \mathrm{C} ; T_{a}$ ambient temperature at $T_{w}\left({ }^{\circ} \mathrm{C}\right) ; \Delta t$ the required time to achieve $T_{w}, \mathrm{~s}, A_{p}$ the aperture area, $\mathrm{m}^{2}$

\subsubsection{Specific boiling time (ts) and characteristic boiling time (tc)}

The specific boiling time, $t_{s}\left(\min . \mathrm{m}^{2} / \mathrm{kg}\right)$ is the required time to boil $1 \mathrm{~kg}$ of water by using a solar cooker with $1 \mathrm{~m}^{2}$ of aperture area, whereas the characteristic boiling time, $t_{c}\left(\min . \mathrm{m}^{2} / \mathrm{kg}\right)$ was used as an important parameter for making comparisons among several solar cooker designs under different values of solar radiation intensity. Specific boiling time and characteristic boiling time can be determined using relation given by (Khalifa et al., 1985)

$$
t_{s}=\frac{\Delta t A_{p}}{M} \quad t_{c}=\frac{t_{s} \bar{I}_{s}}{I_{s}^{*}}
$$

Where:

$\bar{I}_{s}$ is the average solar radiation intensity for the time period $\Delta t\left(\mathrm{~W} / \mathrm{m}^{2}\right)$ and ${ }^{*} \mathrm{Is}$ is the reference average solar radiation intensity, i.e. $900 \mathrm{~W} / \mathrm{m}^{2}$.

\section{RESULTS AND DISCUSSION}

\section{1-The first figure of merit (F1)}

For the solar cooker, the first figure of merit $(F 1)$ is a very important indicator for better thermal performance. The higher value of $F 1$ means the increase in the optical efficiency on the account of the total heat loss coefficient which is very desirable. In other words, the F1 determines the capability of the solar cooker for capturing a large amount of solar radiation due to the good optical properties of the cover with minimum 
losses from the cooking compartment to the surrounding. In the present study, the $F 1$ value was estimates by performing the stagnation temperature test for the prototype Quonset-shape solar cooker in passive mode by subjecting the cooker with the conventional absorber plate (CAP) and the black stone bed (BSB) without load (no pot) to the solar radiation in clear sky and sunny days throughout the period from 10:00 to 14:00 (Standard procedure by Funk, 2000) until internal parts of cooker attained the stagnation state, where the average value for the two compartment was taken into consideration. As exhibits in Fig.(3), this test was carried out during two consecutive experimental days with close average values for both the ambient temperature $\left(T_{a}\right)$ and solar radiation intensity (SRD). In the first day, the results show that the maximum temperature of the CAP $\left(T_{C A P}\right)$ was about $110^{\circ} \mathrm{C}$ attained at 13:00 under SRD of $797.1 \mathrm{~W} / \mathrm{m}^{2}$ and $\mathrm{T}_{\mathrm{a}}$ of $32.5^{\circ} \mathrm{C}$. Whereas, the maximum temperature of the BSB $\left(T_{B S B}\right)$ was about $122{ }^{\circ} \mathrm{C}$ attained at $13: 40 \mathrm{pm}$ under SRD of $770 \mathrm{~W} / \mathrm{m}^{2}$ and $\mathrm{T}_{\mathrm{a}}$ of $30^{\circ} \mathrm{C}$ in the second day.

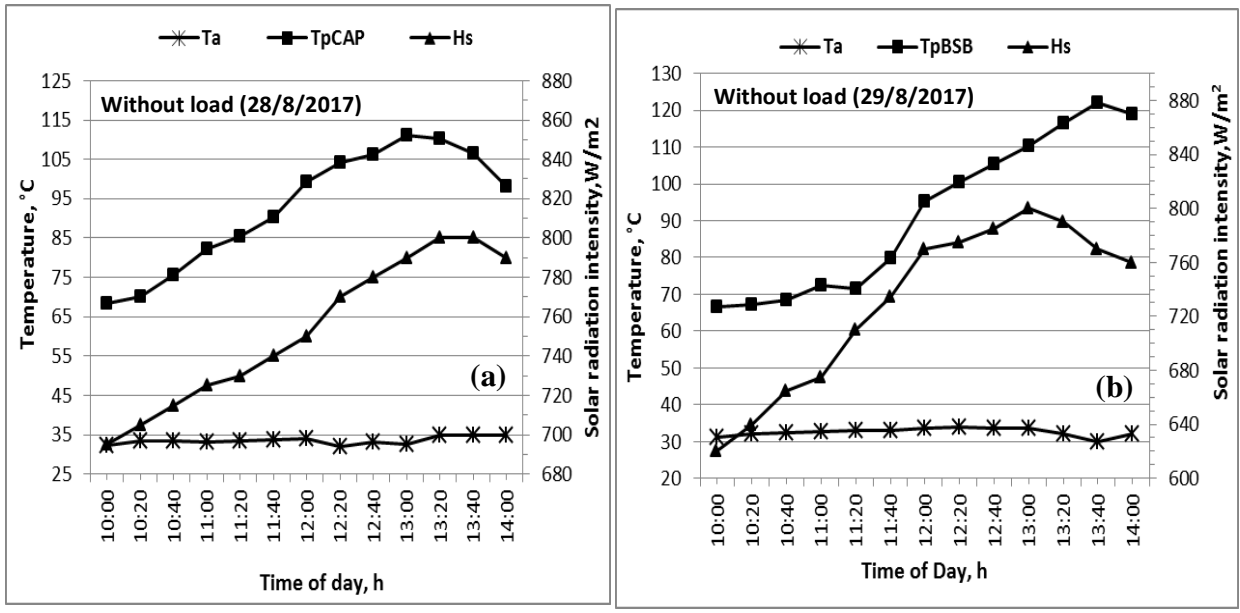

Fig.(3): The variation of solar radiation intensity, temperatures of ambient, a) the CAP and b) the BSB of solar cooker during the stagnation test.

As the solar radiation trend, the temperature of CAP was increased rapidly during the forenoon period and its maximum value at afternoon and before the peak of SRD by 20 min and earlier than the BSB by about 
$40 \mathrm{~min}$, after that it tends to declined. On the contrarily, the temperature of the BSB was increased very slightly in forenoon period and reached the maximum value lately with and tends to be stable at the end of test with an increment in temperature more than CAP estimated at 10\%.This can be attributed to the high specific heat of the stones in addition to low thermal conductivity and high transmissivity of the fiberglass cover. (Mullick, et al.1987) The $F 1$ was calculated to be 0.115 and 0.120 ${ }^{\circ} \mathrm{C} . \mathrm{m}^{2} / \mathrm{W}$ for the prototype of solar cooker with $\mathrm{CAP}$ and BSB, respectively. Due the $F 1$ value for the solar cooker with BSB is equal the minimum level of the thermal performance $\left(0.16 \geq F 1 \geq 0.12^{\circ} \mathrm{C} . \mathrm{m}^{2} / \mathrm{W}\right)$ and with CAP was very close to the level .Hence, the cooker with CAP and BSB are considered efficient and had a good thermal performance.

\section{2- The temperature variations during the full load experiments}

In the present work, the variation of the temperatures for the solar cooker with CAP and BSB under the passive and active modes were investigated throughout cooking period provided with full load till the boiling range under different water's masses $\left(\mathrm{m}_{\mathrm{f}}\right)$ of 0.5 , 1and $1.5 \mathrm{~kg}$ during consecutive experimental days that extended from $21 / 8$ to $1 / 9 / 2017$, as illustrated in Figs. (4-7). The prototype solar cooker under the mentioned conditions was placed in sunny and clear sky conditions from 9:00 to 15:00 in every experimental day. The temperatures of the different cooker components including the conventional absorber plate $\left(T_{C A P}\right)$, black stone bed $\left(T_{B S B}\right)$, enclosure air $\left(T_{e}\right)$, water $\left(T_{w}\right)$, inner surface of cover $\left(T_{c i}\right)$ and the ambient $\left(T_{a}\right)$ were measured every 20 min intervals. Regarding the passive cooker with the conventional absorber plate, the temperatures of $T_{C A P}$ and $T_{e}$ were higher than $T_{w}$ at the forenoon period from 9:00 to 11:00 for water masses of 0.5 and $1.5 \mathrm{~kg}$, while this period extended about 20 min for water mass of $1.5 \mathrm{~kg}$ and then the temperature of $T_{w}$ increased rapidly comparing with the increase occurred in the $T_{C A P}$ and $T_{e}$ till its peak value at afternoon before the declination at the end of the experimental day, as shown in Fig.(4).It is clear that, the increase of water mass will slow down the heating rate especially in the morning under relatively low solar radiation intensity comparing to the noon period. 

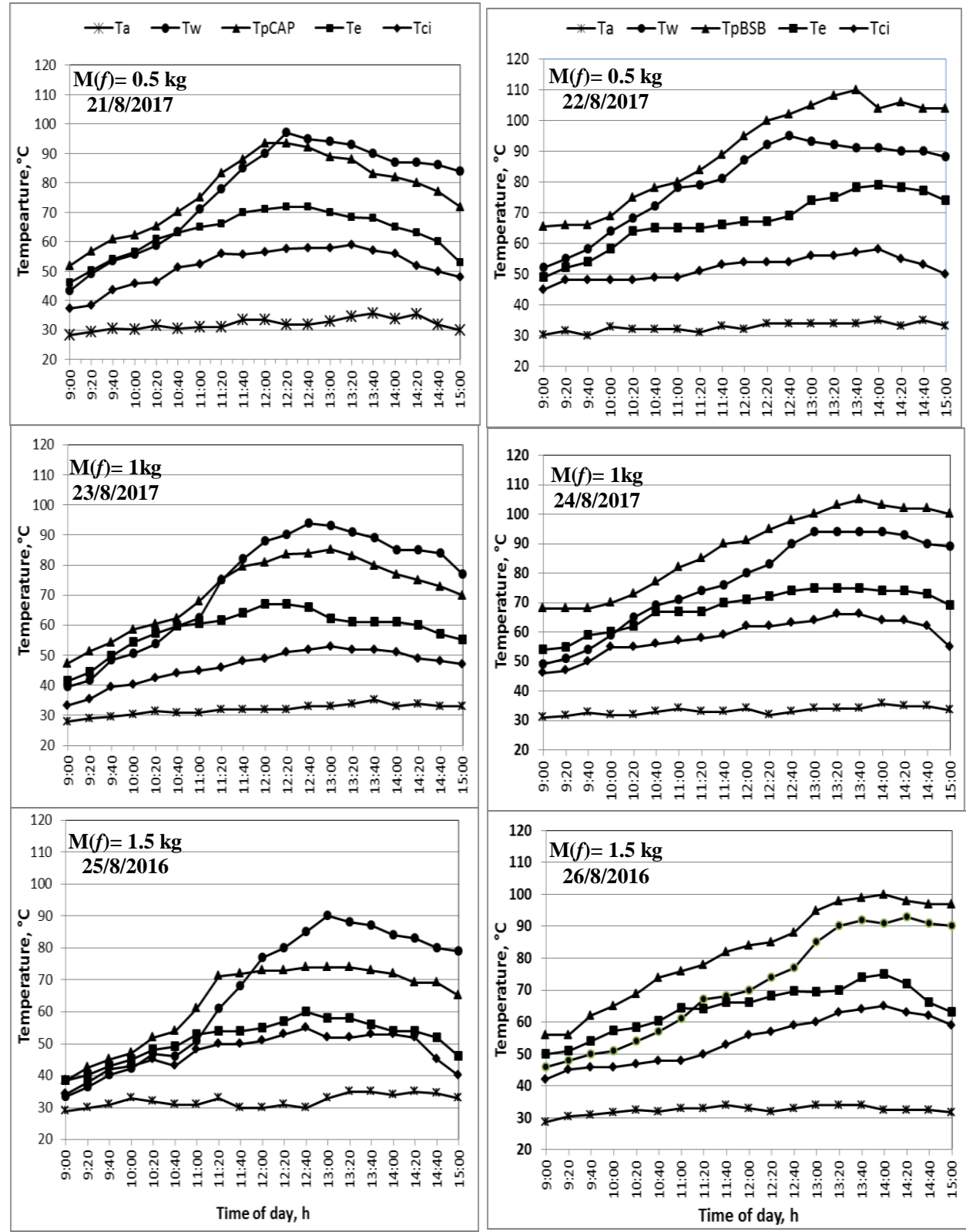

Fig.(4): Temperature variation for Fig.(5): Temperature variation for the passive solar cooker with CAP using different water masses

the passive solar cooker with BSB using different water masses

Simultaneously, the $T_{c i}$ values were very close to the $T_{e}$ at beginning of the experimental day under the different masses of water with a gradual increase around noon and it tends to decreased at the end of the 
experiment time in similar behavior of $T_{e}$. This can be attributed to the diminished solar long waves emitting by the internal component of cooker during the morning hours. Apparent declination in $T_{w}$ was observed at afternoon, particularly for the lower water mass. For cooker with the black stone bed, the obtained data indicated that the temperature of $T_{B S B}$ was higher than the $T_{e}$ and $T_{w}$ throughout the experimental day regardless to water mass with a quasi-steady state within the first hour of the test, then it tends to remain high temperature over the absorber plate for relatively long time during the afternoon and late period of the day, as displayed in Fig.(5). This can be referred to the huge heat capacity of the black stone pebbles. It was observed that, the $T_{e}$ increased slightly during the forenoon period but it tends to reach its peak at the end of the test. Despite the remarkable lag for the progress of $T_{w}$ values comparing to the passive CAP, the BSB can achieve close values for $T_{w}$ in the boiling range $\left(\sim 90^{\circ} \mathrm{C}\right)$ with somewhat delay. Thus, the using of BSB prevents the sharp drop in the $T_{w}$ unlike the CAP because it can hold large amounts of heat for long period during the daylight with the important preference given by the fiberglass cover that can accumulate high amounts of heat within the cooker. Due to the heat capacity increases by increasing the water mass, the results showed that the increase of water mass from 0.5 to $1.50 \mathrm{~kg}$ will prolong the period required to reach the boiling point about $40 \mathrm{~min}$ and decrease temperature from 97 to $90{ }^{\circ} \mathrm{C}(7.21 \%)$ for the CAP. and about $60 \mathrm{~min}$ with slight reduction in temperature from 96 to $92{ }^{\circ} \mathrm{C}$ $(4.16 \%)$ for the BSB. The temperature variation of the integrated cooker with a solar flat-plate collector using the CAP and BSB is depicted in Figs. $(6,7)$.Since the average temperature of output hot water throughout all the experimental days ranging between $75^{\circ} \mathrm{C}$ at the beginning of the experimental day (in mourning) and $88^{\circ} \mathrm{C}$ around the noon, so the active mode secured additional heat gains to the prototype cooker. Concerning to the active solar cooker with CAP, the $T_{C A P}$ increased in faster rate especially during the forenoon period comparing to the passive $\mathrm{CAP}$ and consequently the $T_{w}$ reached its peak values of 96,93 and $92{ }^{\circ} \mathrm{C}$ for the water mass of $0.5,1$ and $1.50 \mathrm{~kg}$, respectively .It is clear that the $T_{w}$ exceed the $T_{C A P}$ and $T_{e}$ earlier than the passive CAP, as demonstrated in Fig.(6). 

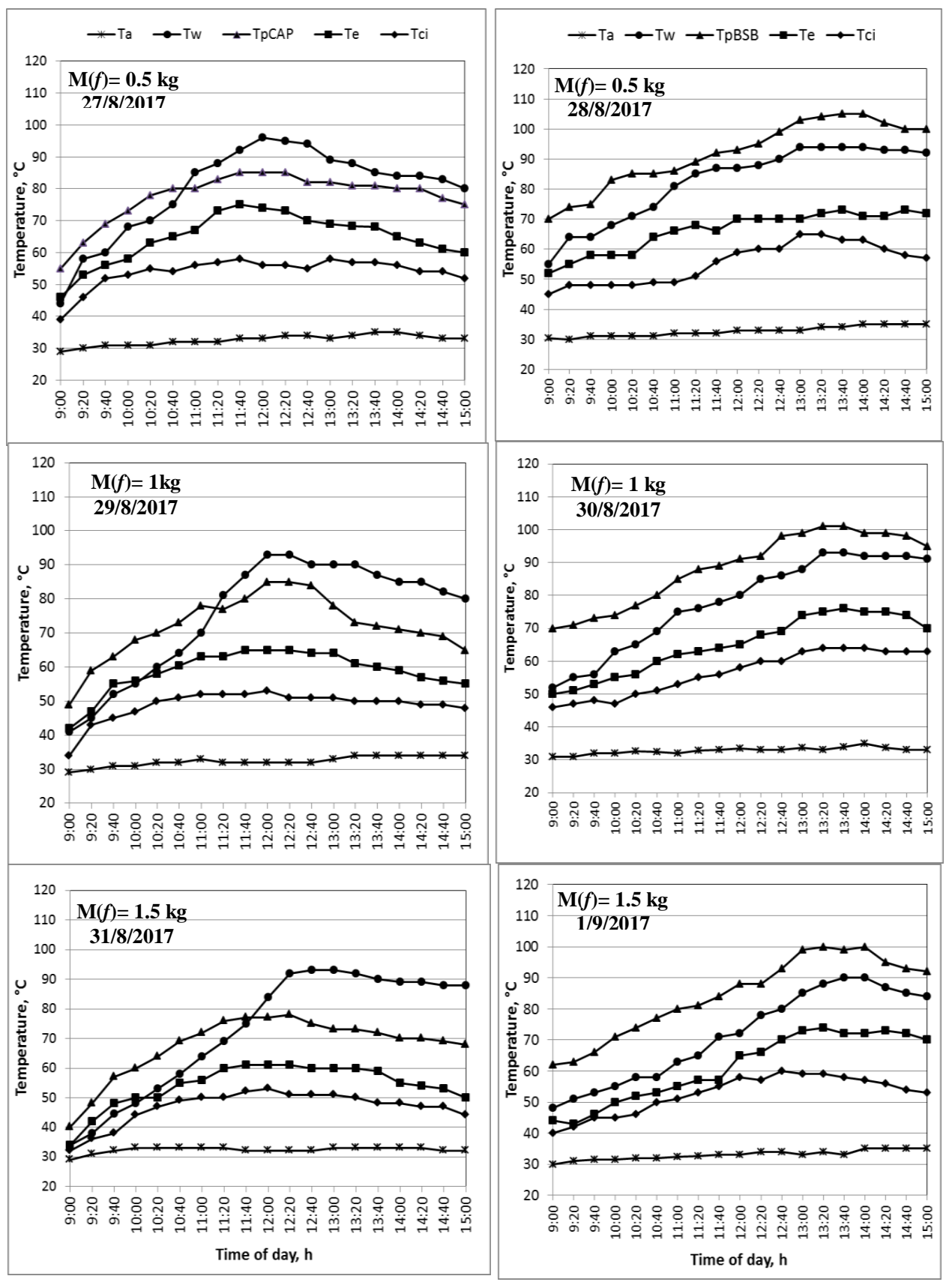

Fig.(6): Temperature variation for the active solar cooker with CAP using different water masses

Fig.(7): Temperature variation for the active solar cooker with BSB using different water masses 
Hence, the active cooker with CAP can achieve very close values for $T_{w}$ to the passive CAP with shortened period, where the saved time through reaching the boiling point was about 20 to 40 min comparing to the passive CAP, but the problem of the water temperature drops in the afternoon period is still exists. It was observed that the $T_{e}$ in the active cooker provided with CAP reached its peak values earlier that that occurred in the passive one due to the temperature of the output hot water supplied by the solar collector is still relatively high in the first two hours of the test day, while the $T_{c i}$ took the same trend of the $T_{e}$. Fig.(7) declared that, providing solar cooker with hot water using BSB will raise the $T_{B S B}$ and give a good start for heating up the BSB during the forenoon period and consequently a rapid increase in $T_{w}$ value was noticed at the first couples of hours. After that the active solar cooker with BSB perform as same as the passive one around noon. Also, it was found that the $T_{w}$ and $T_{B S B}$ were retarded at the end of the experimental day on the contrary of the passive BSB. This because the temperature of BSB is very high around noon comparing to the maximum temperature of the recirculating hot water, accordingly the effect of the outputted hot water of solar collector is diminished and it may absorb portion of the stored heat in the stones in afternoon period, so the cooker become uneconomical. It is obvious that, the active solar cooker with CAP offered a longer period for boiling water than the passive CAP around the noon even for higher water mass, whereas the passive cooker with BSB gave a good thermal performance at afternoon so it is suitable for the evening cooking using black stone pebbles as a heat storage material .Additionally, the integration of the flat-plate solar collector with cooker using BSB has no significant effect.

3- The effect of water mass and operation mode on the overall utilizable efficiency $\left(\eta_{u},\right)$, specific boiling time $\left(t_{s}\right)$ and characteristic boiling time $\left(t_{c}\right)$

Fig.(8) depicts The values of the utilizable efficiency $\left(\eta_{u}\right)$, specific $\left(t_{s}\right)$ and characteristics boiling time $\left(t_{c}\right)$ for the prototype Quonset solar cooker that provided with CAP as well as BSB under the passive and active modes. The obtained results indicated that, the utilizable efficiency $\left(\boldsymbol{\eta}_{u}\right)$ was increased as the mass of water increases under all treatments of this 
work. The data show that, the increase of water mass from 0.5 to $1.5 \mathrm{~kg}$ the utilizable efficiency increased from 12.11 to $26.9 \%$ and from 10.4 to 22.52 for the Quonset solar cooker provided with CAP and BSB, respectively under the passive mode, whereas the utilizable efficiency increased from 13.60 and $36.60 \%$ and from 10.72 to $22.7 \%$ for the solar cooker provided with $\mathrm{CAP}$ and $\mathrm{BSB}$, respectively under the active mode. In other words, the Quonset solar cooker provided with CAP under the active mode achieved a higher utilizable efficiency than passive cooker by about $26.5 \%$ at the high water load of $1.50 \mathrm{~kg}$, while there is no significant difference in the utilizable efficiency of the solar cooker provided with BSB under the passive and active mode. Moreover, the specific boiling time $\left(t_{s}\right)$ and characteristic boiling time $\left(t_{c}\right)$ decreased as mass of water increases under all treatments of this study. To achieve a good thermal performance for the solar cooker, the high utilizable efficiency and low characteristic boiling time is very prospective indicator for a fast cooking process.

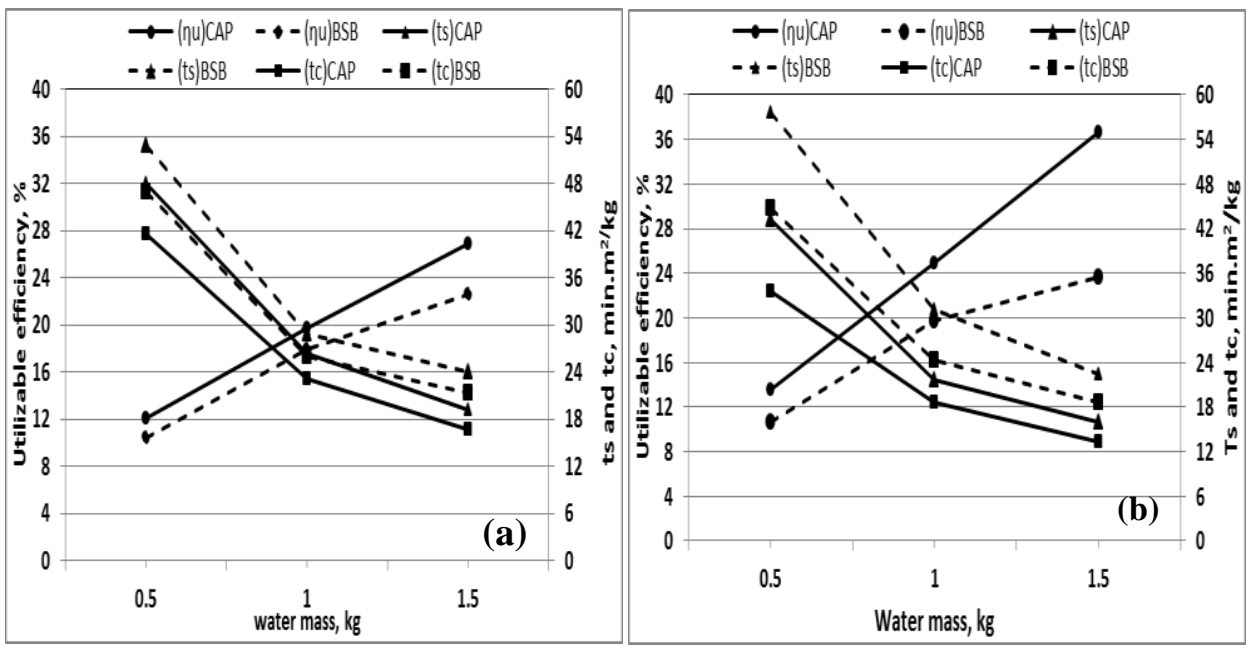

Fig. (8): The utilizable efficiency $\left(\eta_{u}\right.$, specific and $\left(t_{s}\right)$ and characteristic boiling time $\left(t_{c}\right)$ for the solar cooker with CAP and BSB under a) passive and b) active modes under different masses of water

Fig.(8) illustrates that, the solar cooker provided with CAP and aperture area of $1 \mathrm{~m}^{2}$ can boil $1 \mathrm{~kg}$ of water in about 18 and $23 \mathrm{~min}$ at utilizable efficiency of 25 and $19 \%$ under the active and passive modes, 
respectively. So, the active mode reduced the cooking time by about $21.74 \%$ with an increment in the utilizable efficiency of $24 \%$. On the other hand, the solar cooker provided with BSB and aperture area of $1 \mathrm{~m}^{2}$ can boil $1 \mathrm{~kg}$ of water in about 24 and $27 \mathrm{~min}$ at utilizable efficiency of 19 and $17 \%$ under the active and passive, respectively. It is obvious that the integration of the solar cooker using BSB with flat-plate solar collector has no significant effect on the thermal performance of the cooker.

\section{CONCLUSION}

The obtained results show that, the solar cooker provided with BSB stagnation temperature has temperature increment about $10 \%$ more than the CAP and with delay 40 minutes. The first figure of merit was calculated to be 0.10 and 0.12 for the cooker with BSB and CAP, respectively.It is recommended to use the prototype Quonset active solar cooker with the conventional absorber plate (CAP) to achieve a good thermal performance and using the passive cooker with the black stone bed when the evening cooking is concerned, whereas it is not recommended to use the active cooker with black stone pebbles to save the cost of solar collector and the PV system.

\section{REFERENCES}

Akhtar, N., S.C. Mullick (1999).Approximate method for computation of glass cover temperature and top heat-loss coefficient of solar collectors with single glazing. Sol. Energy, 66(5):349-354.

Buddhi, D., S. D. Sharma and A. Sharma (2003). Thermal performance evaluation of a latent heat storage unit for late evening cooking in a solar cooker having three reflectors. Energy Convs. and Manag., 44(6): 809-817.

Cuce, E. and P. M. Cuce (2013). A comprehensive review on solar cookers. Applied Energy. 102 : 1399-1421.

Cuce, E., and P.M. Cuce (2015). Theoretical investigation of hot box solar cookers having conventional and finned absorber plates. Int. J. of Low-Carbon Technol., 10(3), 238-245.

Dudko, K. (2004). Izolacje transparentne w systemie pasywnego ogrzewania słonecznego. Izolacje, 9(1):28-33.(In Polish) 
Funk, P.A. (2000). Evaluating the international standard procedure for testing solar cookers and reporting performance. Sol. Energy, 68(1): $1-7$.

Funk, P.A. and D.L. Larson (1998).Parametric model of solar cooker performance. Sol. Energy, 62(1): 63-68.

Hanan, M.S.E. (2016). Thermal performance of an experimental car-tire solar cooker. Misr J. Ag. Eng., 33 (1): 63 - 74.

Harmim, A., M. Boukar, M. Amar (2008a). Développement et expérimentation d'un cuiseur solaire à double exposition. Revue des Energies Renouvelables, 11(3):371-377.

Harmim, A., M. Boukar, M. Amar (2008b). Experimental study of a double exposure solar cooker with finned cooking vessel. Sol. Energy, 82(4): 287-289.

Harmim, A., M. Belhamel, M. Boukar and Amar M.(2010). Experimental investigation of a box-type solar cooker with a finned absorber plate. Energy, 35:3799-3802.

Hussein, H.M.S., H.H. El-Ghetany and S.A. Nada (2008). Experimental investigation of novel indirect solar cooker with indoor PCM thermal storage and cooking unit. Energy Convs. Manag.,49:2237-2246.

Kalogirou, S. (2003). The potential of solar industrial process heat applications. Appl. Energy, 76:337-61.

Kalogirou, S.A. (2004). Solar thermal collectors and applications. Prog. Energy Combust. Sci., 30:231-295.

Kaushika, N.D. and K. Sumathy (2003). Solar transparent insulation materials: a review, Renew. and Sust. Energy Rev., 7:317-351.

Kerdchang, P. and W. Puangsombut (2008). Conical solar cooker. 6th International Conference on Heat Transfer, Fluid Mechanics and Thermodynamics, Pretoria, South Africa.

Khalifa, A.M.A., M.M.A. Taha and M. Akyurt (1985). Solar cookers for outdoor and indoors. Energy,10(7):819-829.

Kisilewicz, T. (2007). Computer simulation in solar architecture design. Architec. Eng. and Design Manag., 3(2): 106-123 
Lewandowski, W.M. and W. Lewandowska-Iwaniak (2014). The external walls of a passive building: A classification and description of their thermal and optical properties, Energy and Buildings, 69: 93-102.

Mirdha, U.S. and S.R. Dhariwal (2008). Design optimization of solar cooker. Renew. Energy, 33:530-544.

Mullick, S. C.; T.C. Kandpal, and S. Kumar (1996) Testing of boxtype solar cooker: second figure of merit F2 and its variation with load and number of pots. Sol. Energy, 57(5): 409- 413.

Mullick, S.C.; T.C. Kandpal and A.K. Saxena (1987) Thermal test procedure for box-type solar cookers. Sol. Energy, 39(4):353-60.

Muthusivagami, R.M., R. Velraj and R. Sethumadhavan (2010). Solar cookers with and without thermal storage: a review. Renew. Sust .Energy Rev., 14:691-701.

Nahar, N. M. (2001). Design, development and testing of a double reflector hot box solar cooker with a transparent insulation material. Renew. Energy, 23(2): 167-179.

Narasimha Rao, A.V. and S. Subramanyam (2005) Solar cookers part II: cooking vessel with central annular cavity. Sol. Energy, 78:19-22.

Terres, H., A. Lizardi, R. López, M. Vaca and S. Chávez (2014). Mathematical Model to Study Solar Cookers Box-Type with Internal Reflectors. Energy Procedia, 57: 1583-1592.

Valmiki, M. M., P. Li, J. Heyer, M. Morgan, A. Albinali, K. Alhamidi and J. Wagoner (2011). A novel application of a Fresnel lens for a solar stove and solar heating. Renew. Energy, 36(5): 1614-1620.

Wentzel M. and A. Pouris (2007). The development impact of solar cookers: a review of solar cooking impact research in South Africa. Energy Policy, 35: 1909-1919.

Zulovich, J. M. (1993). Active Solar Collectors for Farm Buildings.

Extension publication, Missouri University, USA. 


\section{الملخص العربى}

\section{الأداء الحراري لنموذج أولي للطباخ الثمسي ذو الثكل النصف إسطواني محمد علي توفيق* ويق}

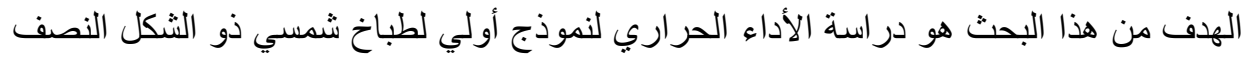

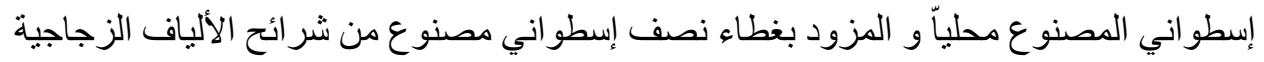

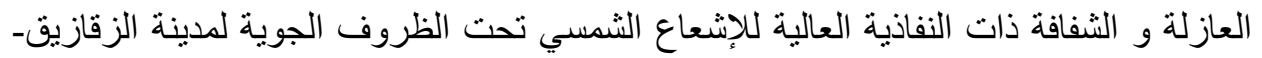

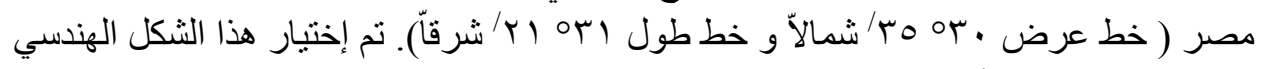
للحصول علي حجم أكبر للحيز الداخلي و بالتالي لزيادة الحرارة المتر اكمة داخل حجرة الطبخ.

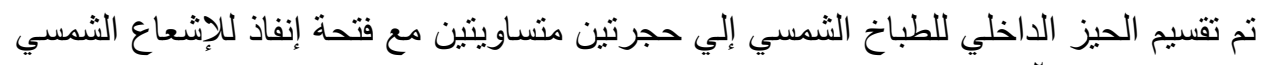

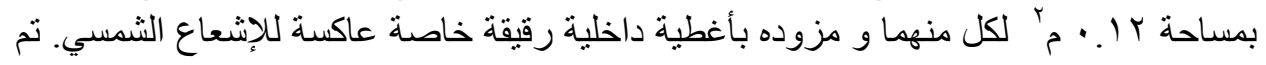
تقييم الأداء الحراري للنموذج التجريبي للطباخ الشمسي بإستخدام لوح الأمتصاص التهدئ التقليدي

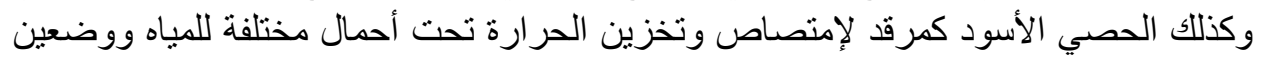

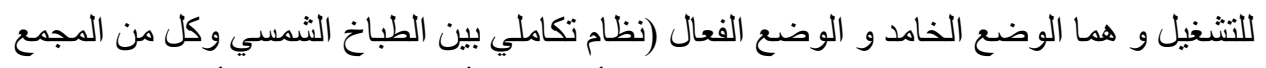

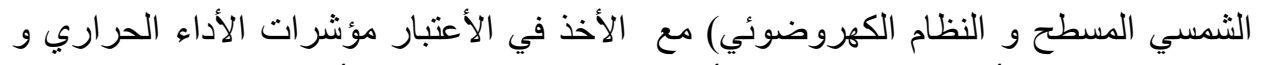

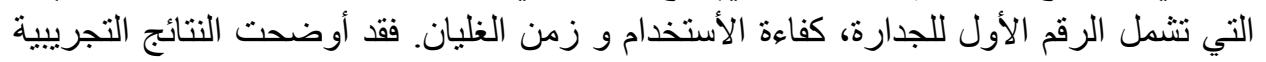

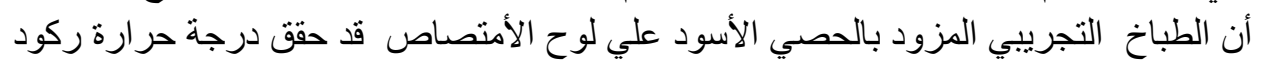

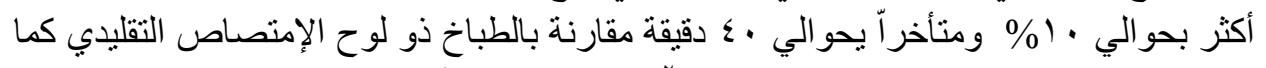

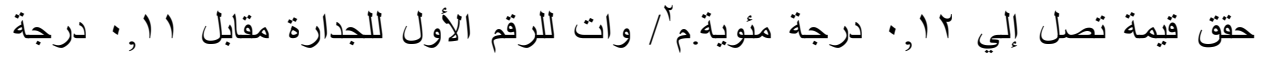

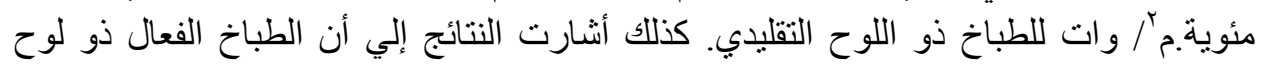

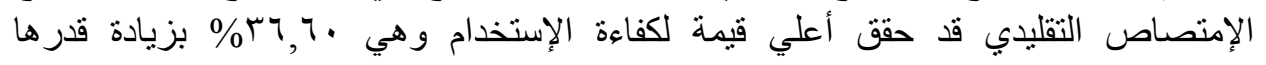

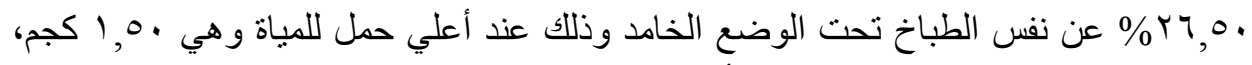

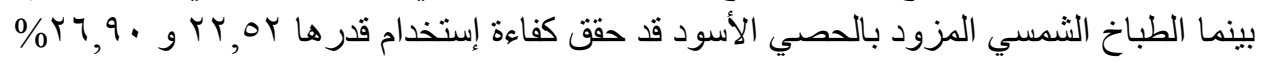

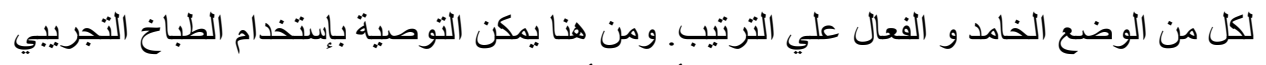

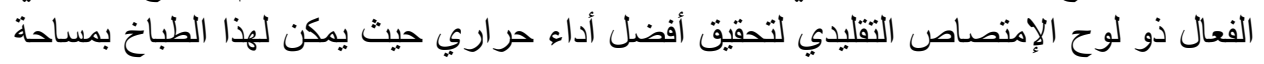

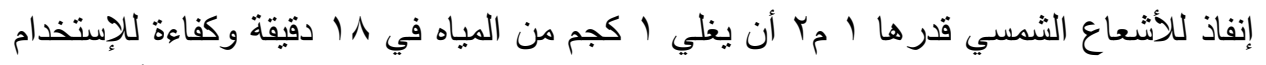

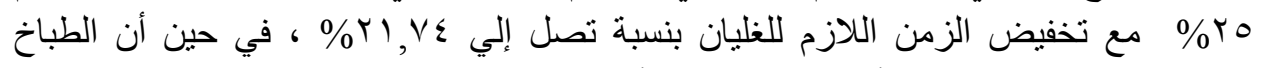

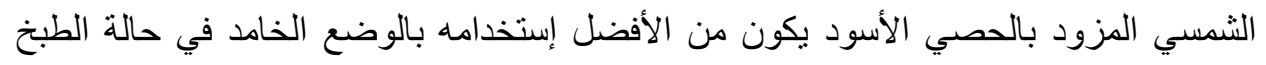

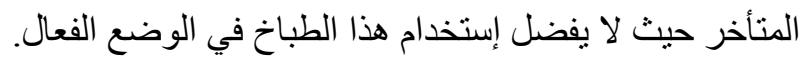

* أستاذ مساعد الهناسة الزراعية ـ كلية الزراعة ـ جامعة الزقازيق ـ مصر. 